\title{
Comparison of Short-term Outcomes of Laparoscopic- Assisted Colon Cancer Surgery Using a Joystick-Guided Endoscope Holder (Soloassist II) or a Human Assistant
}

\author{
Jun Sung Kim, Won Cheol Park, Joo Hyun Lee \\ Department of Surgery, Wonkwang University Hospital, Wonkwang University School of Medicine, Iksan, Korea
}

Purpose: This study aimed to compare the short-term outcomes of laparoscopic-assisted colon cancer surgery in the Soloassist II-assisted (SA) group and in the human-assisted (HA) group.

Methods: A total of 76 patients with colon cancer who underwent laparoscopic-assisted right hemicolectomy and anterior resection performed by a single surgeon between January 2017 and May 2018 were recruited from the consecutively enrolled registry and retrospectively analyzed.

Results: Of 76 patients, 43 underwent surgery with human assistance and 33 underwent surgery using the Soloassist II system. The clinicopathologic characteristics were not statistically different between the 2 groups. In both HA and SA groups, no statistical difference was observed between operation time (220.23 \pm 47.83 minutes vs. $218.03 \pm 38.22$ minutes, $\mathrm{P}=0.829)$, total number of harvested lymph nodes ( $20.42 \pm 10.86$ vs. $20.24 \pm 8.21, \mathrm{P}=0.938)$, and other parameters of short-term outcomes (length of hospital stay, blood loss, open conversion, time to flatus, time to soft diet, and complication events). Subgroup analyses did not show statistical differences.

Conclusion: Soloassist II can reduce the participation of a human assistant during surgery and is not inferior to human assistance in laparoscopic-assisted colon cancer surgery. Thus, it is a feasible instrument in laparoscopic-assisted colon cancer surgery that can provide positive short-term outcomes.

\section{Keywords: Laparoscopy; Colon cancer; Soloassist; Endoscope holder}

\section{INTRODUCTION}

Laparoscopic techniques in general surgery began with appendectomy, introduced by Semm in 1980 [1], and then cholecystectomy, introduced by Mühe in 1985 [2]. Since then, laparoscopic instruments and endoscopes have gradually developed and various surgical procedures have been performed. Laparoscopic-assisted surgery in colon cancer was considered in the 1990s [3].

Received: September 19, 2018 - Accepted: October 18, 2018

Correspondence to: Joo Hyun Lee

Department of Surgery, Wonkwang University Hospital, Wonkwang University School of Medicine, 460 Iksan-daero, Iksan 54538, Korea

Tel: +82-63-859-1490, Fax: +82-63-855-2386

E-mail:mist3284@hanmail.net

ORCID code: https://orcid.org/0000-0002-9888-4451

(C) 2019 The Korean Society of Coloproctology

This is an open-access article distributed under the terms of the Creative Commons Attribution NonCommercial License (http://creativecommons.org/licenses/by-nc/4.0) which permits unrestricted noncommercial use, distribution, and reproduction in any medium, provided the original work is properly cited.
Initially, it was not used widely because of doubts of its oncologic safety and recurrence of trocar wounds. However, large-scale randomized trials confirmed that the oncologic safety of laparoscopic-assisted surgery is not inferior to that of conventional open surgery. These large-scale trials include the clinical outcomes of the surgical therapy study group and the MRC CLASICC (medical research council conventional versus laparoscopic-assisted surgery in colorectal cancer) trial. Laparoscopic-assisted surgery was accepted as a substitute procedure for conventional open surgery due to its advantages of shorter hospital stay and wound minimization [4-6].

The da Vinci robotic surgical system (Intuitive Surgical Inc., Sunnyvale, CA, USA) was recently developed, and several institutions have reported their results. Despite some advantages, the high cost of the procedure has remained a problem [7-10].

An endoscope system is essential in laparoscopic-assisted surgery, and most endoscopes are held by a human assistant. However, as operation time increases, assistants may experience fa- 
tigue and capture unstable images due to tremor. Endoscope holder systems were developed to solve these problems and capture precise images. Initially, these were passive endoscope holders that attach to an endoscope $[11,12]$. Since then, active endoscope holder systems were developed. With the recent development of robotic active endoscope holder systems, surgeons can adjust the endoscope without removing their hands from the instruments $[13,14]$.

The Soloassist II system (AKTORmed, Barbing, Germany), a robotic active endoscope holder system, is a joystick-guided endoscope remote control system [15]. This study aimed to compare the short-term outcomes of laparoscopic-assisted colon cancer surgery in a Soloassist II-assisted (SA) and a human-assisted (HA) groups.

\section{METHODS}

\section{Study population}

A total of 76 patients with colon cancer who underwent laparoscopic-assisted right hemicolectomy (RHC) and anterior resection (AR) performed by a single surgeon at Wonkwang University Hospital between January 2017 and May 2018 were recruited from the consecutively enrolled registry and retrospectively analyzed.

Because our institution has used the Soloassist II system since October 2017, patients were divided into a HA group and a SA group ( $n=43$ and $n=33$, respectively). All patients were diagnosed with colon cancer through pathologic biopsy and underwent elective surgery performed by the same surgeon. There were no inclusion criteria for applying the Soloassist II system. Conversion between HA laparoscopic surgery and SA laparoscopic surgery did not occur. This study was approved by the Institutional Review Board of Wonkwang University Hospital (WKUH 201807-007), and informed consent was waived.

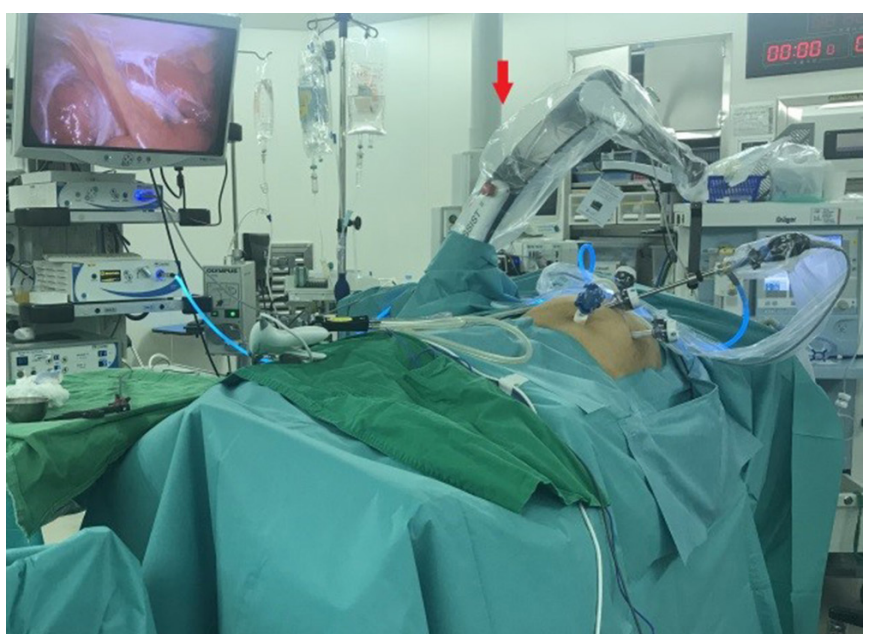

Fig. 1. Positioning of the Soloassist II system in laparoscopic-assisted right hemicolectomy (red arrow).

\section{Soloassist II system}

The Soloassist II system is a robotic active endoscope holder that can be moved by a joystick. It consists of the main body unit, a power unit, a universal joint, an endoscope clamp, and a joystick. It can be attached to the side rail of a surgical bed, and the main body can be covered by a disposable drape. Other settings were comparable to those of conventional laparoscopic-assisted operations, except for the use of the Soloassist II system (Fig. 1). The joystick, endoscope clamp, and universal joint can be reused after sterilization in an autoclave. The Soloassist II system requires adjustment after installation. After insertion of the endoscope trocar, the tip of the endoscope clamp is moved to the trocar site and adjusted by pressing a button on the main body. Then, a surgeon can move the endoscope $360^{\circ}$ using the joystick (Fig. 2). Two small buttons on the joystick move the endoscope forward and backward (zoom in and out). Moreover, the endoscope can be moved manually by holding down the button on the main body.

\section{Surgical procedures}

All surgical procedures were performed using the same method, endoscope, surgical bed, patient position, participant positions, and instrument positions, except for the use of the Soloassist II system in one group. All procedures were performed using standard laparoscopic-assisted surgery via conventional multiport methods. In cases of RHC, the endoscope trocar was inserted into the supra-umbilical area, and two operator ports were placed in the suprapubic area and left lower quadrant (LLQ), respectively. One assistant port was located in the epigastric area. The specimen was extracted via midline mini-laparotomy above the umbilicus. An extracorporeal ileocolic anastomosis was performed with intraluminal staples (ILS). For AR, the endoscope trocar was located on the left of the umbilicus, and 2 operator ports were placed in the right upper quadrant and right lower quadrant, re-

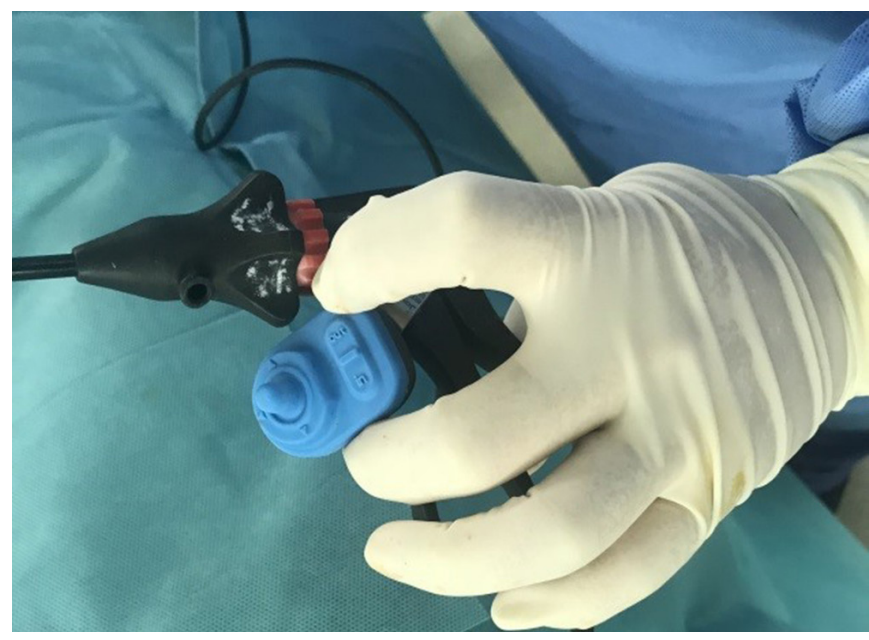

Fig. 2. The surgeon can move the endoscope $360^{\circ}$ using a joystick. 
spectively. One assistant port was inserted into the LLQ area. The sigmoid colon was extracted through mini-laparotomy of the LLQ. Intracorporeal colo-colic anastomosis was performed with ILS inserted through the anus. The HA group included 1 operator and 2 assistants, whereas the SA group included 1 operator and 1 assistant. The operator was an experienced colorectal surgeon who had experience performing laparoscopic-assisted surgery, including robot-assisted surgery ( $>400$ cases). However, he was not experienced in using the Soloassist II system before this study.

\section{Clinical data and study end points}

The primary end point of the study was comparison of early surgical outcomes. Operation time (minutes), postoperative length of hospital stay (LOHS, days), estimated intraoperative blood loss $(\mathrm{mL})$, and complication events were assessed. Operation time was measured in minutes from skin incision to skin suture. LOHS was measured in days from surgery to discharge. Blood loss was assessed by suction volume and gauze weight. Complication events included only grade II or higher complications of the ClavienDindo classification that occurred until the postoperative hospital stay. The total number of harvested lymph nodes (LNs) was eval-

Table 1. Clinicopathologic characteristics of patients

\begin{tabular}{lccc}
\hline Variable & HA $(\mathrm{n}=43)$ & $\mathrm{SA}(\mathrm{n}=33)$ & P-value $^{\mathrm{a}}$ \\
\hline Sex & & & $0.301^{\mathrm{b}}$ \\
Male & $25(58.1)$ & $23(69.7)$ & \\
$\quad$ Female & $18(41.9)$ & $10(30.3)$ & \\
Age (yr) & $68.09 \pm 10.16$ & $71.21 \pm 10.48$ & 0.195 \\
Body mass index (kg/m²) & $24.11 \pm 3.02$ & $24.24 \pm 3.79$ & 0.866 \\
ASA PS classification & & & $0.487^{\mathrm{c}}$ \\
I & $2(4.7)$ & $1(3.0)$ & \\
॥ & $37(86.0)$ & $26(78.8)$ & \\
॥ & $4(9.3)$ & $6(18.2)$ & \\
Previous abdominal operation & $7(16.3)$ & $3(9.1)$ & 0.499 \\
Operation method & & & $0.272^{\mathrm{b}}$ \\
Right hemicolectomy & $18(41.9)$ & $18(54.5)$ & \\
Anterior resection & $25(58.1)$ & $15(45.5)$ & \\
Cancer stage ${ }^{\mathrm{d}}$ & & & $0.503^{\mathrm{c}}$ \\
0 & $1(2.3)$ & $1(3.0)$ & \\
1 & $11(25.6)$ & $11(33.3)$ & \\
2 & $14(32.6)$ & $5(15.2)$ & \\
3 & $15(34.9)$ & $15(45.5)$ & \\
4 & $2(4.7)$ & $1(3.0)$ & \\
\hline
\end{tabular}

Values are presented as number (\%) or mean \pm standard deviation. HA, human-assisted group; SA, Soloassist II-assisted group; ASA PS, American Society of Anesthesiologists physical status classification.

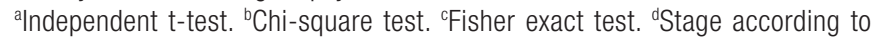
American Joint Committee on Cancer cancer stage manual, 8th edition. uated based on pathologic biopsy results. Open conversion, time to flatus (days), and time to soft diet (days) were also assessed.

Patient demographic data were also analyzed, including age, sex, body mass index, American Society of Anesthesiologists physical status classification, history of previous abdominal operation, operation method, and cancer stage.

\section{Statistical analysis}

Comparisons of continuous variables between the 2 groups were made using independent t-test or Mann-Whitney U-test. The chisquare test and Fisher exact test were used to compare categorical variables. A 2-sided P-value $<0.05$ was considered significant. All statistical analyses were performed using IBM SPSS Statistics ver. 24.0 (IBM Co., Armonk, NY, USA).

\section{RESULTS}

Of 76 patients ( 48 males and 28 females) included in the study, 43 underwent surgery with a human assistant and 33 had surgery with the Soloassist II system. The clinicopathologic characteristics of patients are shown in Table 1. No statistically significant or clinically significant differences were found between the 2 groups.

\section{Short-term outcomes in the HA and SA groups}

Table 2 presents short-term outcomes in the HA and SA groups. Despite the difference in how the endoscope was controlled, there was no difference in operation time between the 2 groups (HA: $220.23 \pm 47.83$ vs. $\mathrm{SA}: 218.03 \pm 38.22, \mathrm{P}=0.829)$. The SA group had less blood loss than the HA group (HA: $79.77 \pm 48.53$ vs. SA: $68.79 \pm 56.22)$; however, there was no statistical difference ( $\mathrm{P}=$ $0.364)$. The total number of harvested LNs was not different between the HA and SA groups $(20.42 \pm 10.86$ vs. $20.24 \pm 8.21, \mathrm{P}=$ 0.938). The open conversion did not occur in either group.

LOHS was not statistically different between groups (HA: $9.93 \pm$

Table 2. Short-term outcomes in human-assisted and Soloassist IIassisted groups

\begin{tabular}{lccc}
\hline Variable & HA $(n=43)$ & SA $(n=33)$ & P-value $^{\mathrm{a}}$ \\
\hline Operation time (min) & $220.23 \pm 47.83$ & $218.03 \pm 38.22$ & 0.829 \\
LOHS (day) & $9.93 \pm 3.07$ & $10.24 \pm 3.19$ & 0.667 \\
Blood loss (mL) & $79.77 \pm 48.53$ & $68.79 \pm 56.22$ & 0.364 \\
Total harvested lymph nodes & $20.42 \pm 10.86$ & $20.24 \pm 8.21$ & 0.938 \\
Open conversion & $0(0)$ & $0(0)$ & \\
Time to flatus (day) & $2.07 \pm 0.46$ & $2.24 \pm 0.50$ & 0.122 \\
Time to soft diet (day) & $5.84 \pm 2.10$ & $5.97 \pm 2.14$ & 0.788 \\
Complication events & $2(4.7)$ & $2(6.1)$ & $1.000^{b}$ \\
\hline
\end{tabular}

Values are presented as mean \pm standard deviation or number (\%).

HA, human-assisted group; SA, Soloassist II-assisted group; LOHS, length of hospital stay.

aIndependent t-test. ${ }^{b}$ Fisher exact test. 
Table 3. Short-term outcomes according to operation method

\begin{tabular}{|c|c|c|c|c|c|c|}
\hline \multirow{2}{*}{ Variable } & \multicolumn{3}{|c|}{ Right hemicolectomy } & \multicolumn{3}{|c|}{ Anterior resection } \\
\hline & $\mathrm{HA}(\mathrm{n}=18)$ & $S A(n=18)$ & P-value ${ }^{a}$ & $H A(n=25)$ & $S A(n=15)$ & P-value \\
\hline Operation time (min) & $231.94 \pm 61.55$ & $221.94 \pm 38.47$ & 0.650 & $211.80 \pm 33.82$ & $213.33 \pm 38.71$ & 0.896 \\
\hline Blood loss (mL) & $101.67 \pm 48.42$ & $87.22 \pm 66.05$ & 0.181 & $64.00 \pm 42.92$ & $46.67 \pm 31.09$ & 0.164 \\
\hline Total harvested lymph nodes & $24.33 \pm 11.22$ & $21.17 \pm 8.36$ & 0.323 & $17.60 \pm 9.87$ & $19.13 \pm 8.17$ & 0.616 \\
\hline Time to soft diet (day) & $6.06 \pm 2.88$ & $6.61 \pm 2.66$ & 0.161 & $5.68 \pm 1.35$ & $5.20 \pm 0.86$ & 0.292 \\
\hline Complication events & $2(11.1)$ & $1(5.6)$ & $1.000^{\mathrm{b}}$ & $0(0)$ & $1(6.7)$ & 0.375 \\
\hline
\end{tabular}

Values are presented as mean \pm standard deviation or number (\%).

HA, human-assisted group; SA, Soloassist II-assisted group; LOHS, length of hospital stay.

alndependent t-test or Mann-Whitney U-test. 'Fisher exact test.

3.07 vs. SA: $10.24 \pm 3.19, \mathrm{P}=0.667)$. No significant differences were identified for time to flatus (HA: $2.07 \pm 0.46$ vs. SA: $2.24 \pm$ $0.50, \mathrm{P}=0.122$ ) or time to soft diet (HA: $5.84 \pm 2.10$ vs. $5.97 \pm 2.14$, $\mathrm{P}=0.788$ ). Postoperative complications occurred in 2 patients from the HA group due to minor anastomosis leakage. In the SA group, 1 patient had postoperative ileus and the other had pleural effusion. All complication events were class II of the ClavienDindo classification. There were no significant differences in complications between the 2 groups $(\mathrm{P}=1.000)$.

\section{Short-term outcomes according to the operation method}

The characteristics of subgroups were not statistically different, even though they were reclassified according to the operative method (data not shown). Table 3 shows short-term outcomes of the subgroup according to the operative method. There was no difference in operation time between the HA and SA groups (RHC: $231.94 \pm 61.55$ vs. $221.94 \pm 38.47, \mathrm{P}=0.650$, AR: $211.80 \pm$ 33.82 vs. $213.33 \pm 38.71, \mathrm{P}=0.896$ ). Subgroup comparisons of other parameters such as LOHS, blood loss, total harvested LNs, open conversion, time to flatus, and complication events revealed no statistical differences.

\section{DISCUSSION}

Laparoscopic endoscopes and instruments have developed gradually over the past 30 years and have various applications in the surgical field. In colon cancer surgery, laparoscopic-assisted surgery is not inferior to conventional open surgery, as shown by large-scale randomized trials. Laparoscopic-assisted surgery provides some advantages, such as shorter hospital stay, surgical wound minimization, and reduced pain $[5,6,16]$.

In laparoscopic-assisted surgery, it is important to acquire precise images to ensure safety. High-resolution endoscopes and even 3-dimensional technology have recently evolved to enable safer and more sophisticated procedures [17]. Despite these tech- nological advances, a human assistant holds most endoscopes. As operation time increases, assistants may experience fatigue and capture unstable surgical images due to tremor. Endoscope holder systems were developed to solve these problems; these were initially designed as passive endoscope holders that attach to an endoscope. These holders had to be moved manually, and surgeons had to interrupt procedures to move the endoscopes $[11,12]$. Therefore, active endoscope holders that can be moved using a surgeon's voice, infrared signals, or a joystick were developed so that surgeons do not need to remove their hands from instruments [18]. One of the first commercially available active endoscope holder systems was the AESOP (Computer Motion, Sunnyvale, CA, USA). Other active endoscope holders included the EndoAssist (Armstrong Healthcare Ltd., High Wycombe, UK), ViKY (EndoControl, Grenoble, France), FIPS Endoarm (Karlsruhe Research Centre, Karlsruhe, Germany), and Soloassist (AKTORmed, Barbing, Germany) [13-15, 19, 20].

Here, we compared the short-term outcomes of the HA and SA groups. Operation time and LOHS were not significantly different between the HA and SA groups (Table 2). In a previous study of cholecystectomy performed using the Soloassist, operation time was significantly shorter in the SA group than in the HA group (HA: $131.4 \pm 57.8$ vs. SA: $107.2 \pm 47.5$ minutes, $\mathrm{P}<0.01$ ) [18]. In another study of Soloassist cholecystectomy, the operation time of the SA group was longer than that of the HA group (HA: median 90 vs. SA: median 104 minutes, $P=0.001$ ) [15]. Similarly, other studies using various active endoscope holders showed a slight increase in operation time. However, most of these studies reported that the use of active endoscope holders decreased the need for a human assistant and increased surgeon satisfaction by providing a stable image. Other parameters that represented surgical outcomes, such as postoperative complications or LOHS, were simi$\operatorname{lar}[15,18,19,21]$. In our experience, there was one fewer assistant needed during surgery. The LOHS, blood loss, and complications of the SA group were not different from those of the HA 
group. The Soloassist II system is not inferior to conventional laparoscopic surgery in quantitative parameters that reflect shortterm outcomes and can provide economic benefit by reducing the need for one assistant to control the endoscope. This system also requires little maintenance cost, except for sterile drapes $[15,18]$. In addition, it can provide a solution for manpower shortage. In Korea, limited manpower in surgical departments has continued due to reduced application to surgical residency [22]. In these circumstances, the Soloassist II system is helpful. Other advantages of Soloassist II included ease of installation and removal. Moreover, it is attached to the side rail of a surgical bed and can easily be changed to a different position as needed. Of course, there were some drawbacks. Image rotation was automatic but not accurate. Trocars sometimes moved unexpectedly while zooming in and out if not tightly fixed. However, these problems were negligible during the operation.

In our experience, the Soloassist II system was easy to learn for inexperienced surgeons. It does not lead to prolonged operation time, increased LOHS, or additional complication events. These results are thought to be the same in all procedures except for those controlled by a joystick. In a previous study of cholecystectomy using the Soloassist, there was no defined learning curve or effect [15]. Similarly, rapid learning curves with active endoscope holders have been presented in other studies $[13,18]$.

We could not compare long-term oncologic outcomes due to the short follow-up period. Instead, the total number of harvested LNs, which is associated with the prognosis of patients with colon cancer, was compared [23-25], and there was no statistical difference between the two groups (Table 2). Because a single surgeon performed the procedures of both groups using the same method, the similar number of harvested LNs in both groups may be associated with the overall oncologic safety of the SA group. However, further studies are needed to evaluate the long-term oncologic outcomes.

This study had several limitations. Although patient characteristics were similar, there were hidden confounders and biases due to the retrospective nature of this study. Next, this study had a small sample size $(n=76)$. Lastly, the long-term outcomes of the 2 groups were not compared because the follow-up period was short. Nevertheless, this was one of the few studies that evaluated the feasibility of using the Soloassist II in laparoscopic-assisted colon cancer surgery.

In conclusion, the use of Soloassist II can decrease the need for a human assistant during surgery and is not inferior to human assistants in laparoscopic-assisted colon cancer surgery. Therefore, Soloassist II is considered a feasible instrument in laparoscopicassisted colon cancer surgery with positive short-term outcomes. However, the long-term oncologic outcomes of laparoscopic-assisted colon cancer surgery using Soloassist II should be evaluated in further studies.

\section{CONFLICT OF INTEREST}

No potential conflict of interest relevant to this article was reported.

\section{REFERENCES}

1. Semm K. Endoscopic appendectomy. Endoscopy 1983;15:59-64.

2. Litynski GS. Erich Mühe and the rejection of laparoscopic cholecystectomy (1985): a surgeon ahead of his time. JSLS 1998;2:3416.

3. Phillips EH, Franklin M, Carroll BJ, Fallas MJ, Ramos R, Rosenthal D. Laparoscopic colectomy. Ann Surg 1992;216:703-7.

4. Berends FJ, Kazemier G, Bonjer HJ, Lange JF. Subcutaneous metastases after laparoscopic colectomy. Lancet 1994;344:58.

5. Clinical Outcomes of Surgical Therapy Study Group, Nelson H, Sargent DJ, Wieand HS, Fleshman J, Anvari M, et al. A comparison of laparoscopically assisted and open colectomy for colon cancer. N Engl J Med 2004;350:2050-9.

6. Jayne DG, Thorpe HC, Copeland J, Quirke P, Brown JM, Guillou PJ. Five-year follow-up of the Medical Research Council CLASICC trial of laparoscopically assisted versus open surgery for colorectal cancer. Br J Surg 2010;97:1638-45.

7. Kim CW, Kim CH, Baik SH. Outcomes of robotic-assisted colorectal surgery compared with laparoscopic and open surgery: a systematic review. J Gastrointest Surg 2014;18:816-30.

8. Keller DS, Senagore AJ, Lawrence JK, Champagne BJ, Delaney CP. Comparative effectiveness of laparoscopic versus robot-assisted colorectal resection. Surg Endosc 2014;28:212-21.

9. Yang SY, Roh KH, Kim YN, Cho M, Lim SH, Son T, et al. Surgical outcomes after open, laparoscopic, and robotic gastrectomy for gastric cancer. Ann Surg Oncol 2017;24:1770-7.

10. Yeo HL, Isaacs AJ, Abelson JS, Milsom JW, Sedrakyan A. Comparison of open, laparoscopic, and robotic colectomies using a large national database: outcomes and trends related to surgery center volume. Dis Colon Rectum 2016;59:535-42.

11. Arezzo A, Schurr MO, Braun A, Buess GF. Experimental assessment of a new mechanical endoscopic solosurgery system: Endofreeze. Surg Endosc 2005;19:581-8.

12. Lee YS, Jeon HG, Lee SR, Jeong WJ, Yang SC, Han WK. The feasibility of solo-surgeon living donor nephrectomy: initial experience using video-assisted minilaparotomy surgery. Surg Endosc 2010;24:2755-9.

13. Aiono S, Gilbert JM, Soin B, Finlay PA, Gordan A. Controlled trial of the introduction of a robotic camera assistant (EndoAssist) for laparoscopic cholecystectomy. Surg Endosc 2002;16:126770.

14. Takahashi M, Takahashi M, Nishinari N, Matsuya H, Tosha T, Minagawa Y, et al. Clinical evaluation of complete solo surgery with the "ViKY" robotic laparoscope manipulator. Surg Endosc 2017;31:981-6.

15. Gillen S, Pletzer B, Heiligensetzer A, Wolf P, Kleeff J, Feussner H, 


\section{Coloproctology Jun Sung Kim, et al.}

et al. Solo-surgical laparoscopic cholecystectomy with a joystickguided camera device: a case-control study. Surg Endosc 2014;28: 164-70.

16. Colon Cancer Laparoscopic or Open Resection Study Group, Buunen M, Veldkamp R, Hop WC, Kuhry E, Jeekel J, et al. Survival after laparoscopic surgery versus open surgery for colon cancer: long-term outcome of a randomised clinical trial. Lancet Oncol 2009;10:44-52.

17. Sakata S, Grove PM, Hill A, Watson MO, Stevenson ARL. Impact of simulated three-dimensional perception on precision of depth judgements, technical performance and perceived workload in laparoscopy. Br J Surg 2017;104:1097-106.

18. Ohmura Y, Nakagawa M, Suzuki H, Kotani K, Teramoto A. Feasibility and usefulness of a joystick-guided robotic scope holder (Soloassist) in laparoscopic surgery. Visc Med 2018;34:37-44.

19. Kraft BM, Jäger C, Kraft K, Leibl BJ, Bittner R. The AESOP robot system in laparoscopic surgery: increased risk or advantage for surgeon and patient? Surg Endosc 2004;18:1216-23.

20. Buess GF, Arezzo A, Schurr MO, Ulmer F, Fisher H, Gumb L, et al. A new remote-controlled endoscope positioning system for endoscopic solo surgery. The FIPS endoarm. Surg Endosc 2000; 14:395-9.

21. Gilbert JM. The EndoAssist robotic camera holder as an aid to the introduction of laparoscopic colorectal surgery. Ann R Coll Surg Engl 2009;91:389-93.

22. Kang S, Jo HS, Boo YJ, Lee JS, Kim CS. Occupational stress and related factors among surgical residents in Korea. Ann Surg Treat Res 2015;89:268-74.

23. Le Voyer TE, Sigurdson ER, Hanlon AL, Mayer RJ, Macdonald JS, Catalano PJ, et al. Colon cancer survival is associated with increasing number of lymph nodes analyzed: a secondary survey of intergroup trial INT-0089. J Clin Oncol 2003;21:2912-9.

24. Swanson RS, Compton CC, Stewart AK, Bland KI. The prognosis of T3N0 colon cancer is dependent on the number of lymph nodes examined. Ann Surg Oncol 2003;10:65-71.

25. Sarli L, Bader G, Iusco D, Salvemini C, Mauro DD, Mazzeo A, et al. Number of lymph nodes examined and prognosis of TNM stage II colorectal cancer. Eur J Cancer 2005;41:272-9. 